\title{
Infiltrate and Fibrosis
}

National Cancer Institute

\section{Source}

National Cancer Institute. Infiltrate and Fibrosis. NCI Thesaurus. Code C139155.

A morphologic finding indicating the presence of a cellular infiltrate associated with fibrosis in a tissue sample. 